\title{
LEITE BOVINO E EXTRATO DE SOJA: ASPECTO MICROBIOLÓGICO - NUTRICIONAL DA SUPLEMENTAÇÃO DE PRODUTOS DE ORIGEM ANIMAL COM SOJA
}

\author{
MARIA DE LOURDES RIBEIRO DE SOUZA DA CUNHA ${ }^{1}$ \\ ANTONIO RIBEIRO DA CUNHA² \\ ELISA YOKO HIROOKA ${ }^{3}$
}

CUNHA, M. de L. R. de S. da ; CUNHA, A. R. da ; HIROOKA, E. Y. Leite bovino e extrato de soja: aspecto microbiológico - nutricional da suplementação de produtos de origem animal com soja. Semina: Ci. Agr., Londrina, v.17, n.1, p.99-104, mar. 1996.

RESUMO: O leite, além de ser um alimento fundamental na dieta humana, é um excelente meio para o crescimento microbiano. Entretanto, o custo do leite limitando o consumo pela população de baixo poder aquisitivo tem levado à busca de outras opções alimentares, com ênfase à introdução de produtos à base de soja. A composição química da soja evidencia sua superioridade em relação aos outros vegetais e equivalência aos produtos animais. Porém, os hábitos alimentares constituem fator limitante à aceitação de produtos contendo soja e, na tentativa de difundir o consumo, tem-se estimulado a mistura de derivados de soja com produtos de origem animal. Por outro lado, pouco se sabe sobre o comportamento microbiano nessas misturas, sendo portanto de extrema importância a avaliação do crescimento de microrganismos. Esta revisão discute as características nutricionais e microbiológicas do leite bovino e extrato de soja, com ênfase ao efeito da suplementação de produtos de origem animal com derivados de soja.

PALAVRAS CHAVE: Leite, extrato de soja, microrganismo, suplementação com soja.

\section{NTRODUÇÃO}

Os alimentos de origem animal, incluindo o leite, carne, ovo e queijo são completos por natureza. Entretanto, o elevado custo os tornam fora do alcance de grande parte da população brasileira. Esta repressão qualitativa e quantitativa na aquisição de alimentos indica claramente como solução imediata e viável, o estímulo ao uso de produtos acessíveis, com qualidade nutritiva e de ampla disponibilidade no mercado.

Com esta finalidade, as proteínas vegetais têm se tornado importantes na suplementação de alimentos, em vista de seu baixo preço e alto valor nutritivo, destacando-se as derivadas de soja.

Entretanto, os hábitos alimentares restringem a ampla aceitação de produtos de soja. Com o objetivo de contornar o problema tem-se incentivado a suplementação de produtos de origem animal com derivados de soja.

A par dessa importante medida tecnológica, pouco se sabe a respeito do comportamento microbiano em tais produtos. Além do efeito das condições de processamento, não se pode descartar o efeito da composição do leite bovino e soja, sobre a interação entre as respectivas microbiotas no produto misto.

\section{CARACTERÍSTICAS NUTRICIONAIS DE LEITE BOVINO E EXTRATO DE SOJA}

A composição química do leite conferindo um extremo valor na dieta humana, por outro lado vem a constituir excelente meio para o crescimento microbiano (GILMOUR \& ROWE, 1987).

O leite é constituído de água, gordura, proteínas, lactose e sais minerais, além de pequenas quantidades de enzimas, vitaminas e gases (BANKS et al., 1987). A lactose é o maior constituinte, aparecendo com um teor de 3,6 a $5,5 \%$ e um valor médio de $4,8 \%$ (HARPER \& HALL, 1976; BANKS et al., 1987).

Bioquimicamente, as proteínas exercem função de maior importância; estão numa concentração de 3,4\%, sendo 2,9\% caseínas e $0,5 \%$ proteínas do soro (CERBULIS \& FARRELL, 1975; BANKS et al., 1987). A caseína apresenta-se sob a forma de um complexo constituído de caseinato de cálcio e fosfato; com ponto isoelétrico em pH 4,6 (HARPER \& HALL, 1976; BANKS et al. 1987). As proteínas do soro são constituídas de albuminas e globulinas (HARPER \& HALL, 1976; BANKS et al. 1987), contendo também a lactoferrina, cuja concentração é maior em leite mastítico, já que desempenha papel protetor nas infecções (COUSINS \& BRAMLEY, 1987).

\footnotetext{
Professora do Departamento de Microbiologia e Imunologia, Instituto de Biociências, Universidade Estadual Paulista, UNESP, Rubião Júnior, Botucatu, SP, Brasil, CEP 18618-000, Caixa Postal 510, PBX(0149) 21-2121, Ramal 2058, Fax (0149) 21-3744.

${ }^{2}$ Engenheiro Agrônomo do Instituto de Pesquisas Meteorológicas, Universidade Estadual Paulista, UNESP, Bauru, SP, Brasil, PBX (0142) 30-2111, Ramal 177.

${ }^{3}$ Professora do Departamento de Ciências de Alimentos e Medicamentos, Universidade Estadual de Londrina, UEL, Londrina, PR, Brasil, CEP 86051-990, Caixa Postal 6001, PBX (043) 321-2000, Fax 327-6932.
} 
A fração lipídica do leite bovino é constituída por $98 \%$ de triglicerídeos, seguida de pequenas quantidades de diglicerídeos, monoglicerídeos, colesterol, ácidos graxos livres e fosfolipídeos (BANKS et al., 1987). Embora seja excelente fonte de cálcio, fósforo, vitamina $B 2$ e boa fonte de vitamina $A, B$ e B12, é pobre em ferro e cobre (HARPER \& HALL, 1976).

Por outro lado, o custo do leite bovino tem limitado o seu consumo pela população de baixo poder aquisitivo. Com o intuito de buscar outras opções alimentares, temse dado ênfase à introdução no mercado de produtos à base de soja (CARRÃO-PANIZZI, 1988).

Segundo CARRÃO-PANIZZI $(1987,1988)$, a soja é uma solução viável como fonte protéica complementar, em termos de fortificar a dieta e enriquecer a qualidade dos alimentos, além de ser uma cultura de alta produtividade e de baixo custo.

O seu conteúdo protéico de $40 \%$ permite classificála entre os principais alimentos protéicos (COSTA et al., 1974; WOLF \& COWAN, 1975; COSTA et al., 1976). O valor biológico da soja, baseado no coeficiente de eficiência protéica (CEP) corresponde a $80 \%$ do valor da proteína do leite, já que o CEP da caseína é de 2,50 e da soja, 2.00 (CARRÃO-PANIZZI, 1987; 1988; SFREDO \& CARRÃO-PANIZZI, 1990).

A soja apresenta bom balanceamento de aminoácidos essenciais, porém com baixo teor de metionina e cistina (SHIH, 1970; KAKADE et al., 1972; SNYDER \& KWON, 1987). Contudo, a dieta com uma combinação de soja e cereal complementa, os aminoácidos sulfurados (WOLF, 1972; CARRÃOPANIZZI, 1987; 1988).

Comparando a composição química da soja, evidencia-se sua superioridade em relação aos outros vegetais e equivalência aos produtos animais, apresentando quantidade razoável de minerais, principalmente o ferro em concentração superior à recomendação diária (CARRÃO-PANIZZI, 1988; SFREDO \& CARRÃO-PANIZZI, 1990). Porém, não é uma boa fonte de cálcio e zinco, apresentando cerca de um terço e um quarto respectivamente, da recomendação diária (CARRÃO-PANIZZI, 1987; 1988; SFREDO \& CARRÃO-PANIZZI, 1990). Por apresentar baixo teor de sódio $(260 \mathrm{mg} / 100 \mathrm{~g})$ e elevado teor de potássio $(760 \mathrm{mg} / 100 \mathrm{~g})$, recomenda-se para dietas de tratamento de pressão arterial (CARRÃO-PANIZZI, 1987; 1988; SFREDO \& CARRÃO-PANIZZI, 1990).

A soja é uma boa fonte de vitaminas do complexo $B$, exceto B12, com quantidades significativas de vitaminas E e K. Os grãos maduros de soja apresentam baixos teores de B-caroteno e ácido ascórbico, embora os grãos verdes e os brotos apresentem maiores teores destas vitaminas (SNYDER \& KWON, 1987; CARRÃOPANIZZI, 1988).

A qualidade nutricional da soja é prejudicada pela presença de fatores antinutricionais, que interferem na utilização proteíca pelo organismo (ARKCOLL, 1976; FILISETTI et al., 1977: LIENER, 1981; SNYDER \&
KWON, 1987). O mais estudado é o inibidor de tripsina, que forma um complexo inativo com a enzima, resultado em hipertrofia pancreática,

seguida de inibição do crescimento (ARKCOLL, 1976; FILISETTI et al., 1977: LIENER, 1981; SNYDER \& KWON, 1987). Entretanto, esses inibidores podem ser inativados pelo calor úmido, já que 30 minutos a $1000 \mathrm{C}$ destroe $90 \%$ de sua atividade (SNYDER \& KWON, 1987; JAIN, 1988). Outros fatores termolábeis presentes na soja são as antivitaminas, fitatos e hemaglutininas (LIENER, 1981).

A soja é constituída de $30 \%$ de carboidratos, sendo $5 \%$ de sacarose, $1 \%$ de rafinose e $4 \%$ de estaquiose (WOLF \& COWAN, 1975; SNYDER \& KWON, 1987). A rafinose e a estaquiose causam a flatulência (HYMOWITZ et al., 1972; LIENER, 1981; SNYDER \& KWON, 1987), limitando, o uso da soja na dieta humana, principalmente por serem termoestáveis (LIENER, 1981; CARRÃO-PANIZZI, 1987).

Muita polêmica tem sido gerada sobre a utilização do leite de soja (FERREIRA et al., 1986; JAIN, 1988). O Quadro 01 apresenta a composição química de leite bovino e de soja.

O leite de soja apresenta o dobro de ferro e quantidade equivalente de fósforo em relação ao bovino. Porém é pobre em vitaminas $A, C$ e cálcio, que aparece em quantidades três vezes inferior, necessitando-se de suplementação, para ser utilizado na dieta de lactantes (CARRÃO-PANIZZI, 1987, 1988). $\mathrm{Na}$ dieta de crianças de 1 a 4 anos é desnecessária a suplementação do leite de soja, uma vez que a alimentação já é suficientemente diversificada (CARRÃO-PANIZZI, 1987).

Considerando que uma grande parte da população não recebe leite e, que a produção não atende à necessidade da população brasileira torna-se evidente a introdução do leite de soja como uma opção nutritiva e de baixo custo (CARRÃO-PANIZZI, 1987).

\section{CARACTERÍSTICAS MICROBIOLÓGICAS DO LEITE BOVINO}

Os microrganismos encontrados no leite variam em número e espécie, dependendo da criação, ordenha, higiene e saúde dos animais (ZALL, 1987; BUSANI \& OLIVEIRA, 1989). Ao deixar a glândula mamária, o leite sofre contaminação proveniente do homem, ambiente, equipamentos e utensílios da ordenha, filtragem, armazenamento e distribuição (COUSIN, 1982; ZALL, 1987); os microrganismos multiplicamse rapidamente, se a temperatura for favorável (ZALL, 1987; VASAVADA, 1988; BUSANI \& OLIVEIRA, 1989).

A situação agrava-se quando os equipamentos não são adequadamente limpos e sanitizados, já que os resíduos de leite proporcionam excelentes nutrientes para o crescimento bacteriano, inclusive de patógenos (COUSIN, 1982; ZALL, 1987). 
A microbiota do leite subdivide-se em duas categorias, a de leite cru e a de produtos lácteos (ZALL, 1987). Os grupos associados ao leite cru constituemse dos gêneros Pseudomonas, Brucella, Escherichia, Salmonella, Lactococcus, Bacillus, Listeria, Corynebacterium, Micobacterium, Arthrobacter, Flavobacterium, Lactobacillus, Campylobacter, além de bolores e leveduras (COUSIN, 1982; GILMOUR \& ROWE, 1987; COUSINS \& BRAMLEY, 1987; VASAVADA, 1988).

\section{QUADRO 1 - Composição química do leite bovino e do leite de soja}

Composição

média (100g)

\begin{tabular}{lrrrr}
\hline Calorias & 52.0 & 429.0 & 63.0 & 450.5 \\
Proteína (g) & 3.4 & 41.8 & 3.1 & 28.7 \\
Gordura (g) & 2.3 & 20.3 & 3.5 & 21.7 \\
Carboidrato (g) & 2.5 & 28.0 & 5.0 & 35.1 \\
Cálcio (mg) & 40.0 & 275.0 & 114.0 & 909.0 \\
Fósforo (mg) & 105.0 & 674.0 & 102.0 & 708.0 \\
Ferro (mg) & 1.2 & 5.0 & 0.1 & 0.5 \\
Vitamina A (ug) & 0.0 & 4.0 & 38.0 & 270.0 \\
Vitamina B1(ug) & 40.0 & 300.0 & 40.0 & 290.0 \\
Vitamina B2(ug) & 120.0 & 250.0 & 653.0 & 1460.0 \\
Niacina (mg) & 0.1 & 0.4 & 0.2 & 0.7 \\
Vitamina C (mg) & 0.0 & 0.0 & 1.0 & 6.0 \\
\hline
\end{tabular}

FONTE: FRANCO (1986), CARRÃO-PANIZZI (1988)

Uma das precauções tomadas para impedir a multiplicação de contaminantes é a refrigeração no transporte e armazenagem (OLIVEIRA \& PARMELLE, 1976; FAIRBAIRN \& LAW, 1986). Todavia, a manutenção do leite e derivados em baixa temperatura seleciona bactérias psicrotróficas (KRAFT \& REY, 1979; COUSIN, 1982; FAIRBAIRN \& LAW, 1986; ZALL, 1987) que sintetizam enzimas termorresistentes, reduzindo a vida de prateleira (COUSIN, 1982). Os gêneros freqüentemente encontrados são Pseudomonas, Flavobacterium, Alcaligenes, Achromobacter e Bacillus (ZALL, 1987, COUSINS \& BRAMLEY, 1987).

O processo de pasteurização garante a consenvação do leite em condições satisfatórias (BUSANI \& OLIVEIRA, 1989). Entretanto, a qualidade da pasteurização depende da matéria-prima e destroe apenas os patógenos (BRYAN, 1983; BUSANI \& OLIVEIRA, 1989).

A alteração pós-pasteurização pode ser decorrente do crescimento de microrganismos que sobreviveram ao tratamento térmico ou contaminação pós-tratamento (BANKS et al., 1987). A microbiota predominante é formada pelos bacilos Gram-positivos esporulados, que sobrevivem ao tratamento térmico e bacilos Gramnegativos, em caso de contaminação pós-pasteurização (NELSON, 1987).
Por outro lado, a utilização de altas temperaturas para garantir a qualidade do produto propicia condições para o desenvolvimento de patógenos quase como em cultura pura, devido à eliminação de microrganismos competidores (DELAZARI, 1979).

O leite pasteurizado com contagem viável reduzida, e o leite em pó, onde o tratamento térmico elimina os competidores, possibilita o desenvolvimento de organismos potencialmente patogênicos. Conseqüentemente, uma contaminação do produto através de manuseio inadequado permite o crescimento de Staphylococcus aureus, em número suficiente para causar intoxicação (DONNELY et al., 1968; DELAZARI, 1979).

\section{CARACTERÍSTICAS MICROBIOLÓGICAS DE SOJA E PRODUTOS DERIVADOS}

A região externa dos cereais contém uma microbiota variável, composta de microrganismos naturais do vegetal, bem como de contaminantes do solo, ar e água (SEMENIUK, citado por LEITÃO, 1981). Esta microbiota é constituída principalmente de bactérias, com predominância das famílias Pseudomonadaceae, Micrococcaceae, Lactobacillaceae e Bacillaceae (FRAZIER, 1976). Entre as leveduras, os gêneros Candida, Sporotrichume Torulopsis são os mais comuns, relatando-se frequentemente também os bolores dos gêneros Penicillium, Colletotrichum, Aspergillus, Alternaria, Helminthosporium, Fusarium, Cladosporium e Mucor (SEMENIUK, citado por LEITÃO, 1981).

As bactérias potencialmente patogênicas não estão associadas às matérias-primas, sendo provenientes de contato com manipuladores ou equipamentos contaminados (LEITÃO, 1981).

Os estudos de contaminação da soja e produtos derivados por microrganismos deterioradores ou patogênicos são escassos (LEITÃO, 1981). EIROA et al. (1975) constataram a presença de Saureus e Clostridium perfringens em 10 e $30 \%$, respectivamente, nas amostras de farinha comercializadas no Brasil. DELAZARI et al., (1978) constataram a contaminação por B. cereus em $29,21 \%$ das amostras de farinha de soja.

EIROA et al. (1977) pesquisando a variação da microbiota no processamento do extrato de soja, verificaram uma população de bactérias mesófilas relativamente elevada nas fases de maceração e desintegração, com valores acima de $104 \mathrm{UFC/g}$. A microbiota adquirida no campo prolifera durante a maceração, já que a matéria-prima permanece na água. Durante o cozimento se reduz para $101 \mathrm{UFC} / \mathrm{g}$, com posterior ascenção para $104 \mathrm{UFC/g}$, na fase de formulação. Após a esterilização do produto nenhuma das amostras apresentou sinais de deterioração (EIROA et al., 1977).

Em estudo realizado por BELL \& SHELEF (1978), a proteína de soja texturizada seca (PSTS) apresentou uma contagem de 4,0 x 103 UFC/g, aumentando-se para 6,0 x 
103 UFC/gimediatamente após a reidratação. A estocagem por 10 dias a $4^{\circ} \mathrm{C}$ elevou a contagem de mesófilos para 107 UFC/g, mas ainda assim, as bactéras não se desenvolveram tão rapidamente, se comparada à carne moída (THOMPSON et al., 1978; DRAUGHON, 1980).

STANSBURY (citado por DRAUGHON, 1980) encontrou em PTS contagens de bactérias aeróbias, mesófilas e psicrotróficas, em quantidades menores do que $102 \mathrm{UFC/g}$ e, quanto aos coliformes totais, estreptococos e estafilococos, em torno de $10 \mathrm{UFC} / \mathrm{g}$.

THOMPSON et al. (1978) obtiveram resultados similares em flocos de proteína texturizada de soja reidratada (PSTR), encontrando menos de $10 \mathrm{UFC} / \mathrm{g}$ para proteolíticos, coliformes e estafilococos.

\section{ASPECTOS MICROBIOLÓGICOS DA SUPLEMEN- TAÇÃO DE PRODUTOS DE ORIGEM ANIMAL COM DERIVADOS DE SOJA}

A limitação do consumo de soja no Brasil deve-se aos hábitos alimentares da população (COSTA et al., 1976). Uma alternativa viável para o incremento da utilização de produtos de soja tem sido a suplementação em carnes, ovos, peixes, frutos marinhos e laticínios (DRAUGHON, 1980; SILVA, 1982; RESENDE, 1987; SOUZA et al., 1988; KARLESKIND et al., 1991). Entretanto, a combinação de proteínas vegetais e animais aumenta o crescimento microbiano, resultando em diminuição do tempo de prateleira (BELL \& SHELEF, 1978; THOMPSON et al., 1978; DRAUGHON, 1980).

Vários fatores contribuem para o intenso crescimento microbiano nas misturas contendo soja, tais como a suplementação de micronutrientes, ferro e vitamina do complexo $\mathrm{B}$, além do aumento de aminoácidos livres, carboidratos e minerais (KEETON \& MELTON, 1978; DRAUGHON, 1980).

Segundo DRAUGHON (1980), as escolas constituem-se nos maiores usuários de proteína vegetal, sendo portanto de extrema importância, a avaliação de bactérias causadoras de toxinfecções em alimentos suplementados com soja.

Entre as bactérias patogênicas relacionadas com a suplementação de proteína destacam-se $C$. perfringens, C. botulinum, Vibrio parahaemolyticus, $S$. aureus, e Bacillus cereus, sendo o C. perfringens o mais investigado (DRAUGHON, 1980). BUSTA \& SCHRODER (1971), analisando o efeito de proteínas de soja no crescimento de $C$. perfringens, em meio líquido e carne verificaram que a adição de PST e farinhas de soja não aumentaram o crescimento, ocorrendo o contrário com isolado protéico.
Segundo SOFOS et al. (1979), a presença de nitrito em salsicha formulada com carne e PST retardou a produção de toxina botulínica, porém nos produtos contendo isolado, o mesmo mostrou ser ineficiente.

THOMPSON et al. (1978) e BEEL \& SHELEF (1978) verificaram que a suplementação de carne moída com proteína texturizada de soja (PST) aumentou a contagem de microrganismos proteolíticos e de estafilococos, havendo uma redução de 2,2 dias na vida útil do produto a $4^{\circ} \mathrm{C}$. A mistura de carne com PST apresentou maior contagem de psicrotróficos, anaeróbios, Streptococcus sp e Staphylococcus $s p$ do que a carne pura (BEEL \& SHELEF, 1978).

CUNHA-SOUZA (1992) comparando o crescimento de $S$. aureus, $B$. cereus e Pseudomonas aeruginosa em leite bovino, extrato de soja e mistura de ambos verificou um aumento da contagem na mistųra de leite bovino com extrato de soja, em relação ao leite e extrato de soja puros.

A suplementação de produtos marinhos com proteínas de soja vem sendo comercialmente aceita, mas existem estudos referentes apenas ao Vibrio parahaemolyticus, com a estimulação de seu crescimento com a adição de 5 a $10 \%$ de PST (BEUCHAT e JONES, citado por DRAUGHON, 1980).

RESENDE (1987) verificou um efeito promotor da proteína texturizada de soja sobre o B. cereus em carnes bovina e suína suplementadas.

JUDGE et al. (1974), CRAVEN E MERCURI (1977) e SILVA (1982) relataram que proteínas de soja na carne moída estimularam a multiplicação microbiana total, resultando numa contagem superior à das carnes puras e derivados de soja.

\section{CONCLUSÕES}

Os dados relatados por vários autores nos levam a concluir que embora o lançamento de produtos suplamentados com soja melhoraram o valor nutricional e reduziram o custo para o consumidor, favoreceram o desenvolvimento de microrganismos potencialmente patogênicos. Em suma, cuidados devem ser tomados com as novas formulações alimentares advindas de suplementação com produtos vegetais, principalmente em relação a microrganismos causadores de toxinfecções. Tentativas de introduzir alimentos de elevado teor nutritivo para as populações carentes devem-se levar em consideração, as condições de manutenção de produtos preparados, em vista da situação precária dos locais onde normalmente são previstas as distribuições. 
CUNHA, M. de L. R. de S. da, CUNHA, A. R. da, HIROOKA, E. Y. Bovine milk and soybean: microbiological and nutritional interaction resulted from the mixture of both componentes. Semina: Ci. Agr., Londrina, v.17, n.1, p.99-104, mar. 1996.

ABSTRACT: Besides being one of the most important food in human diet, the milk is also an excellent environment for the microbial growth. However, the high cost of the milk restricting the consumption by the low profit population, has led to the use of soybean - based products. The soybean chemical composition proves its superiority comparing to other vegetables and its equivalence to animal products, but the alimentary habits have restricted its acceptance. In order to improve the consumption, encouragement is given to mix soybean components and animal origin products. The influence of the mixture on the microbial growth resulted from the interaction of both ingredients is extremely important for the food preservation. The review reports the nutritional and microbial aspects of milk and soybean extract, with emphasis on the effect of addition of soybean components to the animal origin products.

KEY-WORDS: Milk, soybean, microorganism, supplementation with soybean.

\section{REFERÊNCIAS BIBLIOGRÁFICAS}

ARKCOLL, D.B. Inibidores nutricionais da soja. Bol. Inst. Tecnol. Aliment., Campinas, v.48, p.31-47, 1976.

BANKS, W., DALGLEISH, D.G., ROOK, J.A.F. La leche y su procesado. In: ROBINSON, R.K. Microbiologia lactologica: Microbiologia de la leche. Zaragoza: Acribia, 1987. V.1, cap.1, p.1-32.

BELL, W.N., SHELEF, L.A. Availability and microbial stability of retail beef-soy blends. J. Food Sci., Chicago, v.43, p.315-318, 1978.

BRYAN, F.L. Epidemiology of milborne diseases. J. Food Protect., Ames, v. 46, p.637-649, 1983.

BUSANI, S.F.B., OLIVEIRA, J.S. Leite pasteurizado - sua qualidade desde a fonte de produção. Col. Ital, Campinas, v.19, n.2, p.113$120,1989$.

BUSTA, F.F., SCHRODER, D.J. Effect of soy proteins on the growth of Clostridium perfringens. Appl. Microbiol., Washington, v.22, p.177-183, 1971.

CARRÃO-PANIZZI, M.C. Proteína para milhões. Ciência Hoje, São Paulo, v.6, n.33, p.25-31, 1987.

. Valor nutritivo da soja e potencial de utilização na dieta brasileira. Londrina: EMBRAPA, 1988. 13p.

CERBULIS, J., FARRELL JUNIOR, H.M. Composition of milks of dairy cattle. I. Protein, lactose, and fat contents and distribution of protein fraction. J. Dairy Sci., Champaign, v.58, n.6, p.817-827, 1975.

COSTA, S.I., MIYA, E.E., FUJITA, J.T. Composição química e qualidades organolépticas e nutricionais das principais variedades de soja cultivadas no Estado de São Paulo. Colet. Inst. Tecnol. Aliment., Campinas, v.5, p.305-319, 1974.

COSTA, S.I., QUAST, D.Q., MORETTI, V.A. et al. O emprego da soja na alimentação humana. Bol. Inst. Tecnol. Aliment., Campinas, v.46, p.1-25, 1976.

COUSIN, M.A. Presence and activity of psychrotrophic microorganisms in milk and dairy products: review. J. Food Protect, Ames, v.45, n.2, p.172-207, 1982.

COUSINS, C.M.; BRAMLEY, A.J. Microbiologia de la leche cruda. In: ROBINSON, R.K. Microbiologia lactologica: Microbologia de la leche. Zaragoza: Acribia, 1987. v.1, cap.4, p.109-150
CRAVEN, S.E., MERCURI, A.J. Total aerobic and coliform counts in beef-soy and chicken-soy patties during refrigerated storage. $J$. Food Protect, Ames, v.40, p.112-114, 1977.

CUNHA-SOUZA, M.L.R. Estafilococos enterotoxigênicos: efeito de cultura mista em leite, extrato de soja e parâmetros causadores de injúria celular. Londrina: UEL, 1992. 200p. Dissertação (Mestrado em Ciências de Alimentos)- Fundação Universidade Estadual de Londrina, 1992.

DELAZARI, I., LEITÃO, M.F.F., GERALDINI, A.M. et al. Bacillus cereus em alimentos desidratados. Bol. Inst. Technol. Aliment., Campinas, n. 60, p.31-40, 1978.

DELAZARI, I. Aspectos microbiológicos de alimentos desidratados. Bol. Ital, Campinas, v.16, n.3, p.227-260, 1979.

DONNELLY, C.B., LESLIE, J.E., BLACK, L.A. Production of enterotoxin A in milk. Appl. Microbiol., Washington, v.16, p.917-924, 1968.

DRAUGHON, F.A. Effect of plant-derived extenders on microbiological stability of foods. Food Technol., Chicago, v.34, p.69-153, 1980.

EIROA, M.N.U., LEITÃO, M.F.F., LEITÃO, R.F.F. et al. Caracterização microbiológica de farinhas e amidos. Col.Ital, Campinas, v.6, p.459473, 1975.

EIROA, M.N.U., LEITÃO M.F.F., COSTA, S.I. et al. Controle microbiológico no processamento de leite de soja de longa vida. Bol. Ital, Campinas, v.53, p.69-79, 1977.

FAIRBAIRN, D.J., LAW, B.A. Proteinases of psychrotrophic bacteria: their production, properties, effects and control. J. Dairy Res., Chicago, v.53, n.1, p.139-177, 1986.

FERREIRA, V.L.P., SANTOS, L.C., VALLE, J.L.E. Estabilidade e aceitabilidade do leite de soja formulado. Bol. Ital, Campinas, v.23, n.4, p.425-436, 1986.

FILISETTI, T.M.C.C., MANCINI FILHO, J., MARQUEZ, U.M.L. et al. Fatores anti-nutricionais em produtos comerciais de soja. Rev. Farm. Bioquim. Univer. São Paulo, São Paulo, v.15, p.93-108, 1977.

FRAZIER, W.C. Microbiologia de los alimentos. 2.ed. Zaragoza: Acribia, 1976. 512p.

FRANCO, G. Tabela de composição química dos alimentos. Rio de 
Janeiro: Atheneu, 1986. p.145

GILMOUR, A., ROWE, M.T. Microorganismos asociados a la leche. In: ROBINSON, R.K. Microbiologia lactologica: Microbiologia de la leche. Zaragoza: Acribia, 1987. v.1, cap.2, p.33-70

HARPER, W.J.; HALL, C.W. Dairy Technology and engeneering. Westport: AVI., 1976. 631p.

HYMOWITZ, T., COLLINS, F.I., PANCZNER, J. et al. Relationship between the content of oil, protein, and sugar in soybean seed. Agron. J., Madison, v.61, p.613-616, 1972.

JAIN, M. Educating health workers and villagers on the dietary uses of soy foods in Madhya Pradesh, India. Food Nutr. Bull., Tokyo, v.10, n.4, p. $41-44,1988$.

JUDGE, M.D., HAUGH, C.G., ZACHARIAH, G.L. et al. Soya additives in beef patties. J. Food Sci., Chicago, v.39, p.137-139, 1974.

KAKADE, M.L., SIMONS, N.R., LIENER, I.E. et al. Biochemical and nutritional assessment of different varieties of soybeans. J. Agric. Food. Chem, Washington, v.20, n.1, p.87-90, 1972.

KARLESKIND, D., LAYE, I., HALPIN, E. et al. Improving acid production in soy-based yogurt by adding cheese whey proteins and mineral salts. J. Food Sci., Chicago, v.56, n.4, p.999-1001, 1991.

KEETON, J.T., MELTON, C.C. Factors associated with microbial growth in ground beef extended with varying levels of textured soy protein. J. Food Sci., Chicago, v.43, p.1125-1129, 1978.

KRAFT, A.A., REY, C.R. Psychrotrofic bacteria in foods: an update. Food Technol. Chicago, v.33, p.66-71, 1979.

LIENER, I.E. Factors affecting the nutritional quality of soya products. J. Am. Oil Chem. Soc., Champaing, v.58, n.3, p.406-415, 1981.

LEITÃO, M.F.F. Microbiologia do grão de soja e produtos derivados. In: MIYSAKA, S.; MEDINA, J.C.(Ed.) A soja no Brasil. Campinas: Ital, 1981, p.909-915

NELSON, F.E. Microbiologia de la leche comercial. In: ROBINSON,R.K. Microbiologia lactologica: microbiologia de la leche. Zaragoza: Acribia, 1987. V.1, cap.5, p.151-188
OLIVERIA, J.S., PARMELEE, C.E. Rapid enumeration of psychrotrophic bacteria in raw and pasteurized milk. J. Milk Food Technol., Ames, v.39, n.4, p.269-272, 1976.

RESENDE, E.B. Comportamento microbiológico do Bacillus cereus em carnes puras e suplementadas com soja. Londrina: UEL, 1987. 70p. Dissertação (Mestrado em Ciências de Alimentos) - Fundação Universidade Estadual de Londrina, 1987.

SFREDO, G., CARRÃO-PANIZZI, M.C. Importância da adubação e da nutrição na qualidade da soja. Londrina: EMBRAPA, 1990. 57p.

SHIH, U.E. Soybean milk. J. Am. Diet. Assoc., Chicago, v.57, p.520522,1970

SILVA, S.R.C. Aspectos microbiológicos das misturas de carne e soja. Londrina: UEL, 1982. 95p. Dissertação (Mestrado em Ciências de Alimentos) - Fundação Universidade Estadual de Londrina, 1982.

SNYDER, H.E., KWON, T.W. Soybean utilization. New York: AVI Van. Nostrand Reinhold Company, 1987. 346p.

SOFOS, J.N., BUSTA, F.F., ALLEN, C.E. Clostridium botulinum control by sodium nitrite and sorbic acid in various meats and soy protein formulations. J. Food Sci., Chicago, v.44, p.1662-1667, 1979

SOUZA, G., OLIVEIRA, A.J., SHIROSE, I. Aceitabilidade do sabor de iogurte de "leite de soja" adicionado de leite de vaca. Col. Ital, Campinas, v.18, n.1, p.69-75, 1988.

THOMPSON, S.G., OCKERMAN, H.W., CAHILL, V.R. et al. Effect of soy protein flakes and added water on microbial growth (total counts, coliforms, proteolytics, staphylococci) and rancidity in fresh ground beef. J. Food Sci., Chicago, v.43, p.289-291, 1978.

VASAVADA, P.C. Pathogenic bacteria in milk - a review. J. Dairy Sci. Champaign, v.71, n.10, p.2809-2816, 1988.

WOLF, W.J. What is a soy protein: a review. Food Technol., Chicago, v.26, p.44-54, 1972.

WOLF, W.J., COWAN, J.C. "Soybeans as a food source." Cheveland: CRC Press, 1975. 101p.

ZALL, R.R. Control y destruccion de los microorganismos. In: ROBINSON, R.K. Microbiologia lactologica: microbiologia de la leche. Zaragoza: Acribia, 1987. V.1, cap.3, p.71-108. 